\title{
Conspicuity of moving soldiers
}

\author{
Jaap A. Beintema, Alexander Toet*, Sjoerd J. de Vries \\ TNO, Soesterberg, The Netherlands
}

\begin{abstract}
The construction and validation of soldier combat models requires data on the conspicuity of camouflaged targets in the field, and human targets in particular. So far, this data is lacking. Also, it si currently unknown to what degree luminance contrast and motion contribute to target conspicuity. These data are needed to enable the validation and further development of human visual search performance modules in soldier combat models like SCOPE or IWARS. In this study we measured the conspicuity of a person wearing a Dutch army camouflage uniform, while he was either standing still, walking or running along a forest in the background, both for viewing with the naked eye (NE) and for viewing dynamic thermal scene recordings (IR). We varied the viewing distance $(80 \mathrm{~m}$ and $230 \mathrm{~m}$ ), the camouflage pattern (woodland and desert), the type of background (pine-tree and deciduous forest), and season (summer and winter), The IR (thermal) conspicuity of the person was much larger than his NE (visual) conspicuity. In both cases the effects of movement were large and saturated as a function of retinal target speed. For NE, we find large effects of shading that can not explained by local luminance contrast variations. Also for NE, conspicuity was reduced in winter, probably as a result of an increase in scene clutter. The results suggest that conspicuity is not only a function of retinal target motion and global luminance contrast, but also depends on the amount of clutter in the scene.
\end{abstract}

Keywords: conspicuity, search, motion, contrast, models

\section{INTRODUCTION}

The construction and validation of soldier combat models like $\mathrm{SCOPE}^{3}$ or IWARS ${ }^{1}$ requires data on the conspicuity of camouflaged targets in the field, and human targets in particular. So far, this data is lacking. Also, no realistic data are available on the relative contribution of luminance contrast and motion to target conspicuity.

Visual search, with or without the aid of optical or electro-optical instruments, plays a significant role in various types of military operations (e.g. reconnaissance, surveillance, search and rescue). Advance knowledge of human visual search and target acquisition performance is often required to prepare flight scenarios (e.g. for search and rescue operations), and to model mission performance. In military scenarios, camouflage, concealment and deception (CCD) measures are deployed to reduce the visual signature of targets, thereby maximizing the average time needed by an observer to find the target in the scene. TNO developed a new psychophysical procedure to quantify the visual conspicuity of a target in a complex scene. In this approach, target conspicuity is operationally defined as the maximal lateral distance between target and eye-fixation at which the target can be distinguished ${ }^{7}$. This conspicuity measure can quickly be determined in situ, and can be used with full prior knowledge of the target and its location in the scene ${ }^{5}$. It characterizes the extent to which a target stands out from its immediate surroundings. This conspicuity measure predicts human visual search performance in realistic and military relevant complex scenario's ${ }^{5,6}$. Since human visual search and detection performance is directly related to target conspicuity, the availability of conspicuity data is crucial for the development of search and detection modules for combat models.

In this study, we measured the conspicuity of persons in camouflage clothing moving through the field, both with the unaided eye and for instrumented vision using a thermal camera. We also investigated the interaction between velocity, viewing distance and luminance contrast. In addition, we quantified the effects of camouflage type and season. For thermal images we also assessed the effect of day versus night. The data collected in this study will be used for the further development of target detection modules in soldier combat models.

*lex.toet@tno.nl; phone+31-346-356237; fax +31-346-353977; http://lextoet.googlepages.com/

Infrared Imaging Systems: Design, Analysis, Modeling, and Testing XXII, edited by Gerald C. Holst, Keith A. Krapels, Proc. of SPIE Vol. 8014, 801403 - @ 2011 SPIE · CCC code: 0277-786X/11/\$18 · doi: 10.1117/12.884241 


\section{METHODS}

\subsection{Stimuli}

The target was a person wearing a Dutch army uniform (with either a woodland or desert camouflage pattern) who was situated before a forest. The person wore black gloves and covered his head with a a dark panty-cloth to reduce his conspicuity. The effect of motion was tested in three conditions (see Figure 1). In the static (S) condition, the target person stood still, facing the observer. In the movement conditions, the person either walked (W) or ran (R) along the forest. The movement was along a cyclic path to avoid position-dependent (shading) effects. In the nearby scene conditions, the person walked or ran forward and backward in alternation along the forest edge. In the far scene conditions, the person walked or ran in small circles. The maximum speed during a cycle was estimated to be $1.3 \mathrm{~m} / \mathrm{s}$ in the walking $(\mathrm{W})$ and $2.5 \mathrm{~m} / \mathrm{s}$ in the running $(\mathrm{R})$ conditions.
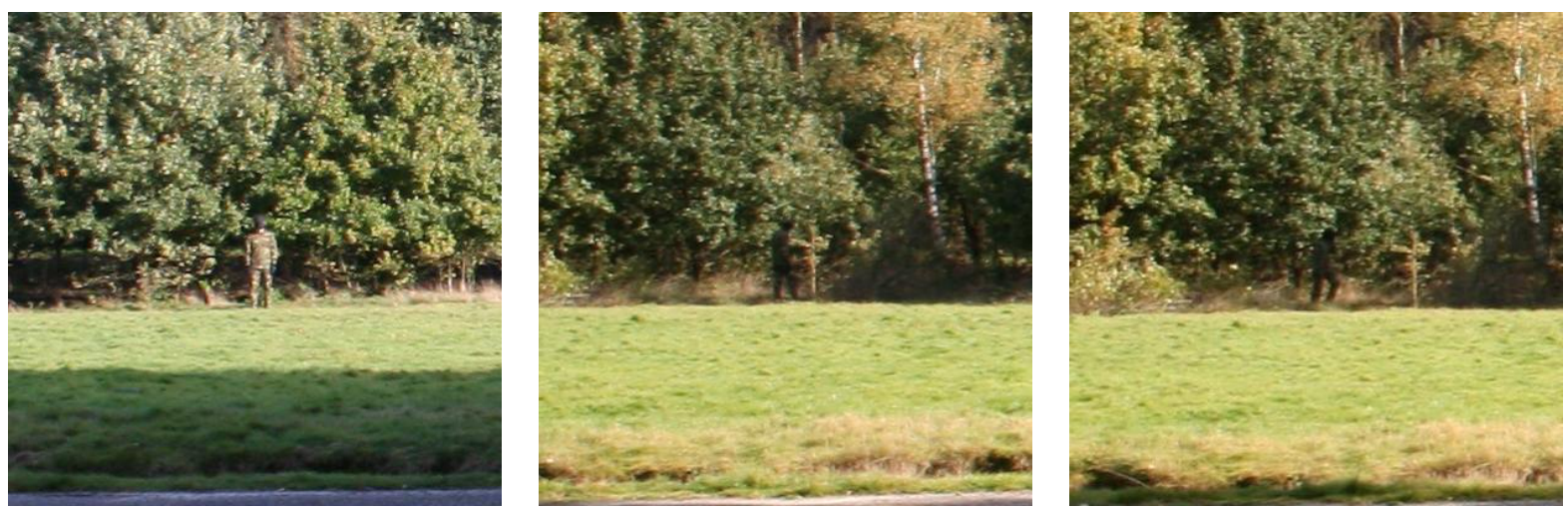

Figure 1. Snapshot of a static (S), walking (W) and running (R) person. Note, the first snapshot is an example of a person in the sun, while the others show a target in the shade of a tree.

Data were collected for two types of scenes near Soesterberg (den Treek $52^{\circ} 05^{\prime} \mathrm{N}, 5^{\circ} 22^{\prime}$ E; Figure 2). The nearby scene was a deciduous forest at the end of a green meadow that measured 80 meters across. The far scene was a coniferous forest at the end of a heath field that measured $230 \mathrm{~m}$ across. Data were captured in two seasons. The first part was collected in early autumn 2008 (October 9th and 10th). The second part was collected in early spring 2009 (9th of April). Since the leaves were still on the trees and had not started to colour in early autumn, and the leaves had not started to grow in early spring, we refer to these conditions as summer and winter, respectively. On all days, visibility was clear with almost no clouds and no wind (1-2 Bft).

Thermal recordings were made with a $320 \times 240$ pixels FLIR camera $\left(24^{\circ}\right.$ horizontal viewing angle) at $50 \mathrm{~Hz}$ or static. Some data collections were repeated in the evening after sunset. The thermal recordings were viewed in the lab on a 19inch CRT monitor $(60 \mathrm{~Hz})$ using Thermacam Researcher with a $16,5 \mathrm{~cm} \times 12,4 \mathrm{~cm}$ window. The average viewing distance was $50 \mathrm{~cm}$. Images were displayed in grey-level mode, with the luminance range set to automatic adjustment. For the motion trials, a full motion cycle was looped.

Scenes were photographed with a digital camera (Canon EOS 400D with 13-44 mm lens). Luminance contrasts for the naked eye were determined from photo's taken during static trials. Pixel grey levels were first converted to luminance levels and then the target luminance contrast was determined from image patches containing the target and from surrounding image areas. 

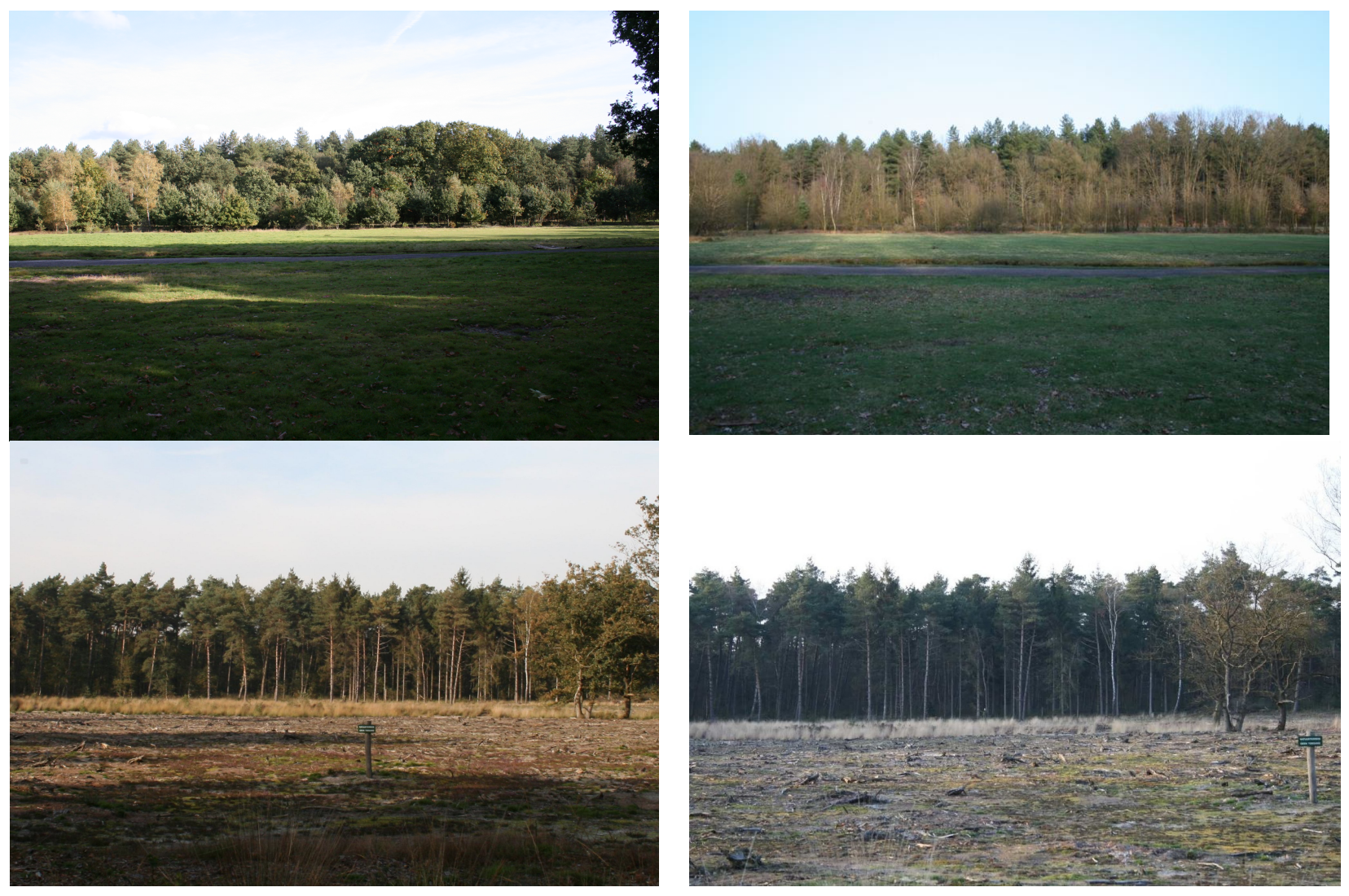

Figure 2. Example images for near scene (deciduous forest) in summer (top-left) and winter (top- right). Below: far scene (coniferous forest) in summer (bottom-left) and winter (bottom-right).

\subsection{Task and procedure}

Conspicuity could be measured accurately, because the target displacement was limited to only a few meters and motion was continuous. After an initial inspection of the target, the observer shifted his fixation point towards one side of the target so that the target was no longer detectable. Then, in staircase-wise manner, the observer shifted fixation until the target was just noticeable in peripheral vision. The observer remembered this critical fixation point from visual landmarks in the scene and measured the angular distance between his critical fixation point and the target location. In field trials, the target eccentricity was measured in angles using binoculars with $1^{\circ}$-precision built-in compasses. In lab trials, the distance between target and fixation position on the screen was measured with a ruler and then scaled to a visual angle based on the camera's viewing parameters. Each measurement was repeated by starting fixation at the opposite side of the target.

For each trial, conspicuity measurements were performed by two highly trained observers. All observers were middleaged (30-50 years) and had normal or corrected-to-normal vision (observers 1-3 wore spectacles). 


\subsection{Experimental design}

An overview of the experiments and varied parameters is given in Table 1. Conspicuity was first measured in the field with the naked eye (NE) . In Experiment I, motion and target position were varied. In Experiment II, motion, viewing distance and type of camouflage was varied. Experiment III was a repetition of experiment I in winter season. Experiment IV was a laboratory test with observations from thermal image (IR) recordings. The IR trials included recordings at the nearby field $(80 \mathrm{~m})$ and far field $(230 \mathrm{~m})$ and the effect of day and night time.

Only a selection of the recordings was presented in the lab test (see Table 2). On day 3, after sunset a low-hanging fog was visible above the deciduous forest scene, so care was taken to select only thermal images that were not affected by the fog.

Table 1. Overview of experimental conditions.

\begin{tabular}{|l|l|l|l|l|l|l|l|}
\hline Season & Summer & Winter \\
\hline Day & $\begin{array}{l}\text { Oct 9th } \\
2008\end{array}$ & Oct 10th 2008 & \multicolumn{4}{l|}{ April 9th 2010} \\
\hline Time of day & Day & Day & Night \\
\hline distance (m) & 80 & $40 / 60 / 80$ & 230 & 80 & 230 & 80 & 230 \\
\hline camouflage & W & W/D & W & W & S/W/R & S \\
\hline velocity & S/W/R & \multicolumn{7}{|l|l|l|l|l|}{} \\
\hline \# positions & 4 & 1 & 8 & 3 & 3 & 3 & 3 \\
\hline \# repetitions & 2 & 1 & 1 & 1 & 1 & 1 & 1 \\
\hline NE trials & yes & yes & yes & yes & yes & no & no \\
\hline \# IR trials & 4 & & 10 & 2 & 1 & 2 & 3 \\
\hline
\end{tabular}

Table 2. Conditions tested for conspicuity from thermal images.

\begin{tabular}{|c|c|c|c|c|c|c|}
\hline Season & \multirow{2}{*}{\multicolumn{2}{|c|}{$\frac{\text { Summer }}{\text { day }}$}} & \multicolumn{4}{|c|}{ Winter } \\
\hline Time of & & & & & & \\
\hline $\begin{array}{l}\text { Viewing } \\
\text { distance }\end{array}$ & $80 \mathrm{~m}$ & $230 \mathrm{~m}$ & $80 \mathrm{~m}$ & $230 \mathrm{~m}$ & $80 \mathrm{~m}$ & $230 \mathrm{~m}$ \\
\hline \#positions & 4 & 10 & 2 & 1 & 2 & 3 \\
\hline Motion & $\mathrm{S} / \mathrm{W} / \mathrm{R}$ & $\mathrm{S} / \mathrm{W} / \mathrm{R}$ & $\mathrm{S}$ & $\mathrm{S}$ & $\mathrm{S}$ & $\mathrm{S}$ \\
\hline Tmin & $10^{\circ}$ & $10^{\circ}$ & $11^{\circ}$ & $11^{\circ}$ & $3^{\circ}$ & $3^{\circ}$ \\
\hline Tmax & $21^{\circ}$ & $24^{\circ}$ & $22^{\circ}$ & $21.3^{\circ}$ & $16^{\circ}$ & $16^{\circ}$ \\
\hline
\end{tabular}

\section{EXPERIMENT I: EFFECT OF TARGET MOTION AND POSITION}

First, the effect of motion was tested and pitted against the effect of natural variation in target and background luminance. The target was a person dressed in a woodland camouflage suit and standing at the edge of deciduous forest (Figure 3). The target was presented at four positions, selected within a horizontal range of $33^{\circ}$. The average viewing distance was $82 \mathrm{~m}$. At each target location, the conspicuity was measured for a stationary (S), walking (W) or running (R) target. At each location conspicuity was measured twice by all observers. Observers also reported whether a target was standing in the shade of trees or in the sun. 

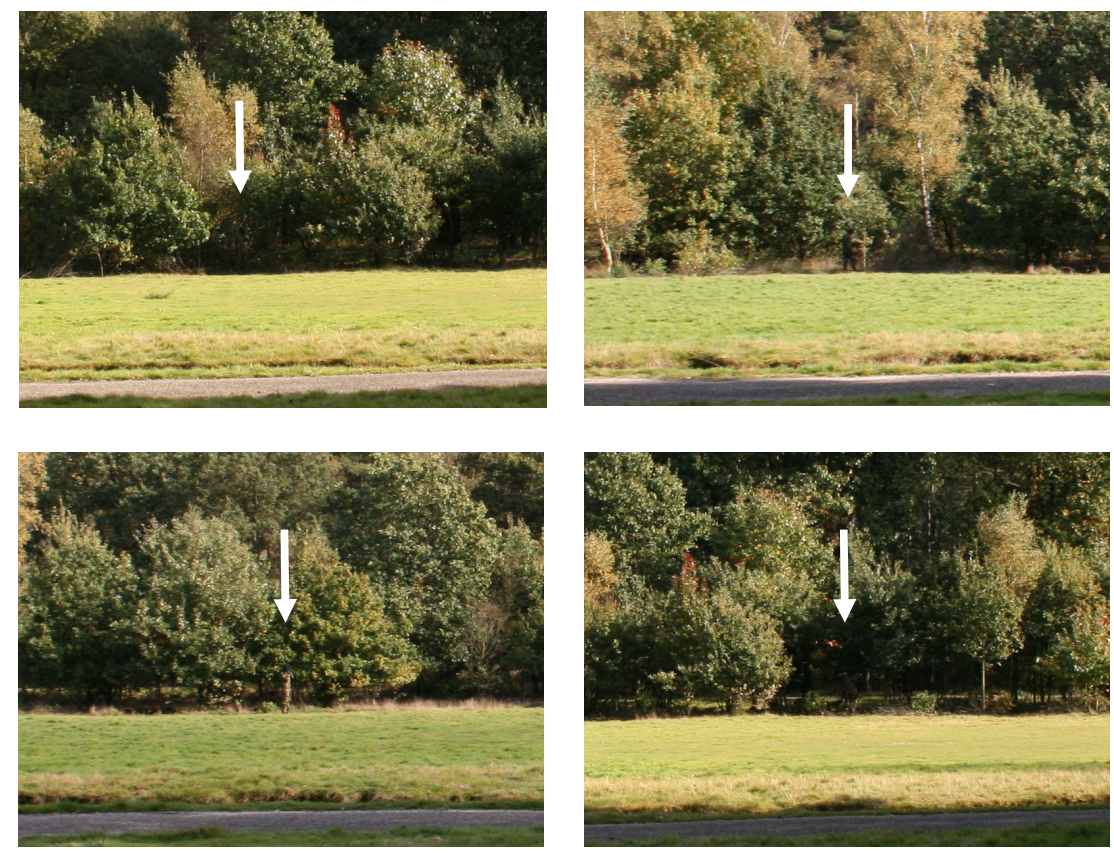

Figure 3. Example images of the target (position indicated by arrow) at position 1 to 4 along the forest.

The results, represented in Figure 4, show two clear effects. First of all, conspicuity increased drastically in motion conditions. The effect was large, even for the lowest conspicuities in the shade of trees. Indeed, the observers complained they lost track of the target as soon as the person stopped moving, and they had to ask the person to move a little in order to relocate the target. The difference between walking and running is much smaller than the difference between walking and static, suggesting a saturation effect. The effect of speed is studied in more detail in the next experiment.

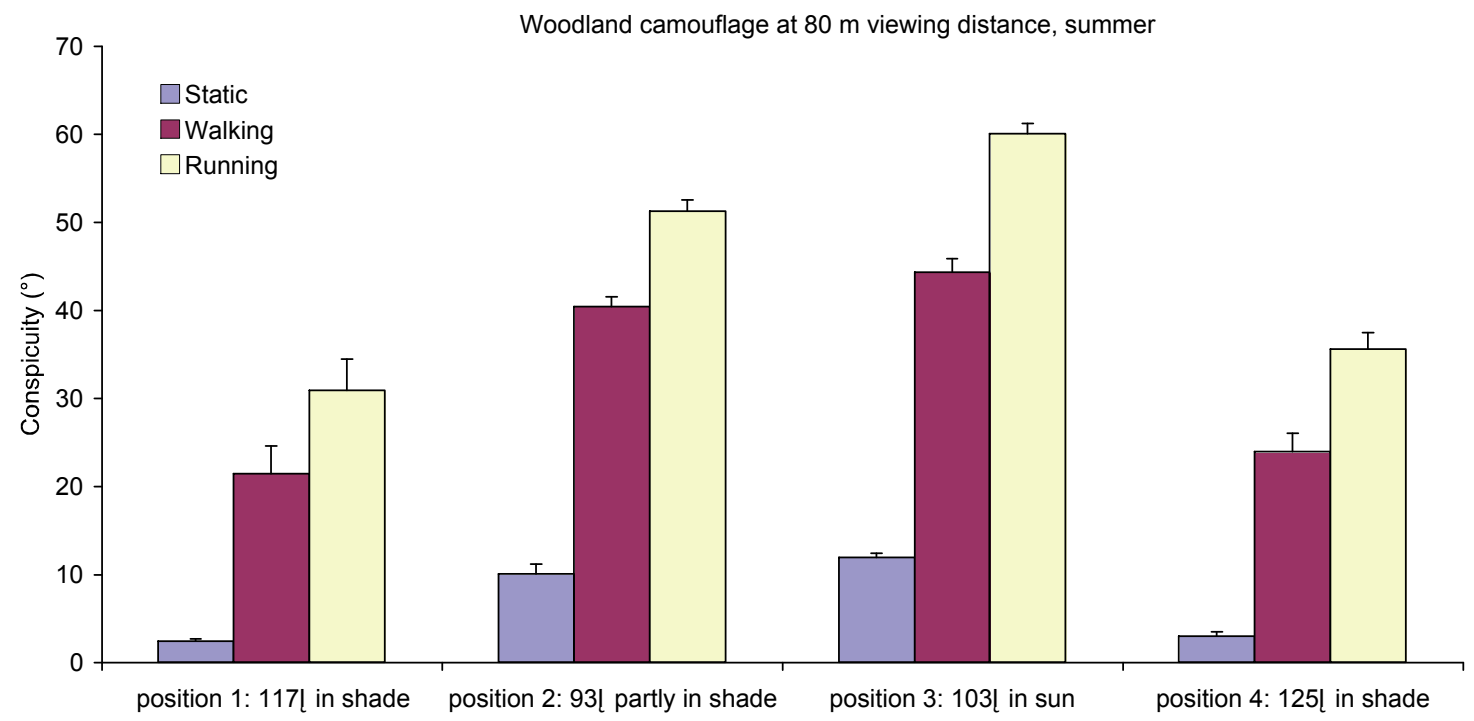

Figure 4. Effect of movement and target position for Woodland camouflage against a deciduous forest. Angles indicate the direction (compass angle). Each bar represents the average $( \pm 1$ S.E.) from two subjects and two measurements. 
Secondly, target position had small, but consistent effects on conspicuity. Most noticeable, targets in the shade of trees were less conspicuous than targets in the sun, both in static and dynamic conditions. To analyse the contribution of luminance contrast, the mean luminance of the target $\left(\mathrm{L}_{\text {target }}\right)$ and the local background $\left(\mathrm{L}_{\text {local }}\right)$ was determined from photo's taken during static trials, according to the following definition:

$$
C_{\text {local }}=\frac{L_{t \arg e t}-L_{\text {local }}}{L_{\text {local }}}
$$

Note, the local luminance was averaged over three circular image areas located immediately left, right and above the target.

Figure 5 (left) shows that the conspicuity increases systematically with local luminance contrast, but the low correlation is rather low $\left(\mathrm{R}^{2}\right.$ between 0.34 and 0.41$)$.
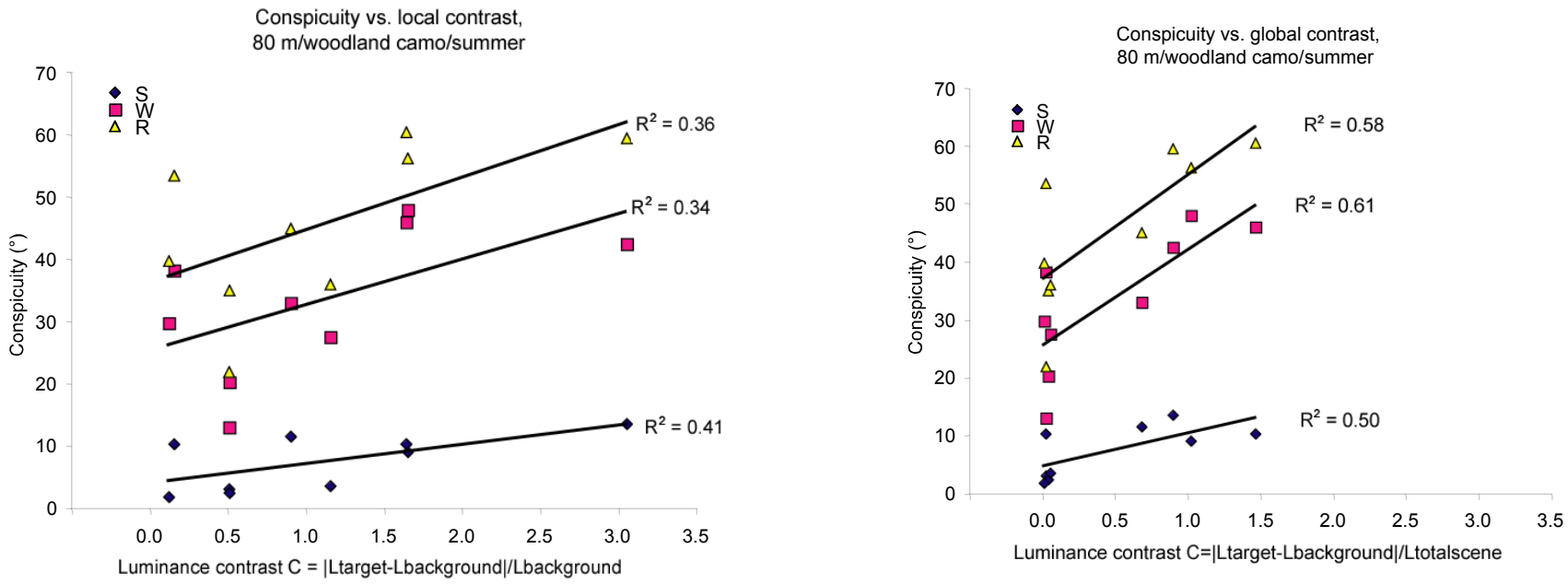

Figure 5. Conspicuity measurements at three velocities as a function of local or global luminance contrast.

Clearly, much of the variation in conspicuity can not be not explained byvariations in local luminance contrast. A possible explanation is that local contrast does not take into account the effect of shadows. A target may have a high local luminance contrast, but if the luminance of the target and local background is much lower than the average scene luminance, the sensitivity to that contrast will still be low. More likely, the contrast sensitivity scales with the scene luminance $\left(\mathrm{L}_{\text {global }}\right)$, averaged over a larger part of the scene. We theferore computed the average luminance over the entire forest area.

$$
C_{\text {global }}=\frac{L_{t \arg e t}-L_{\text {local }}}{L_{\text {global }}}
$$

This global contrast measure yields a higher correlation between conspicuity and contrast $\left(\mathrm{R}^{2}\right.$ between 0.5 and 0.61 : Figure 5, right). We will therefore use this contrast definition throughout the rest of this study. 


\section{EXPERIMENT II: EFFECT OF MOTION, VIEWING DISTANCE AND CAMOUFLAGE}

In the second experiment we investigated the interaction between motion, luminance contrast and viewing distance. Luminance contrast was varied over a large range by dressing the person in a dark uniform (Dutch woodland) and in a much brighter kaki coloured uniform (Dutch desert). The target was at a fixed position in the shade of the trees (compass angle $125^{\circ}$ ). Examples are shown in Figure 6. Viewing distances were 80,60 and $40 \mathrm{~m}$, but the latter distance was not tested with desert camouflage, because the conspicuity angle approached the limits of the visual field.
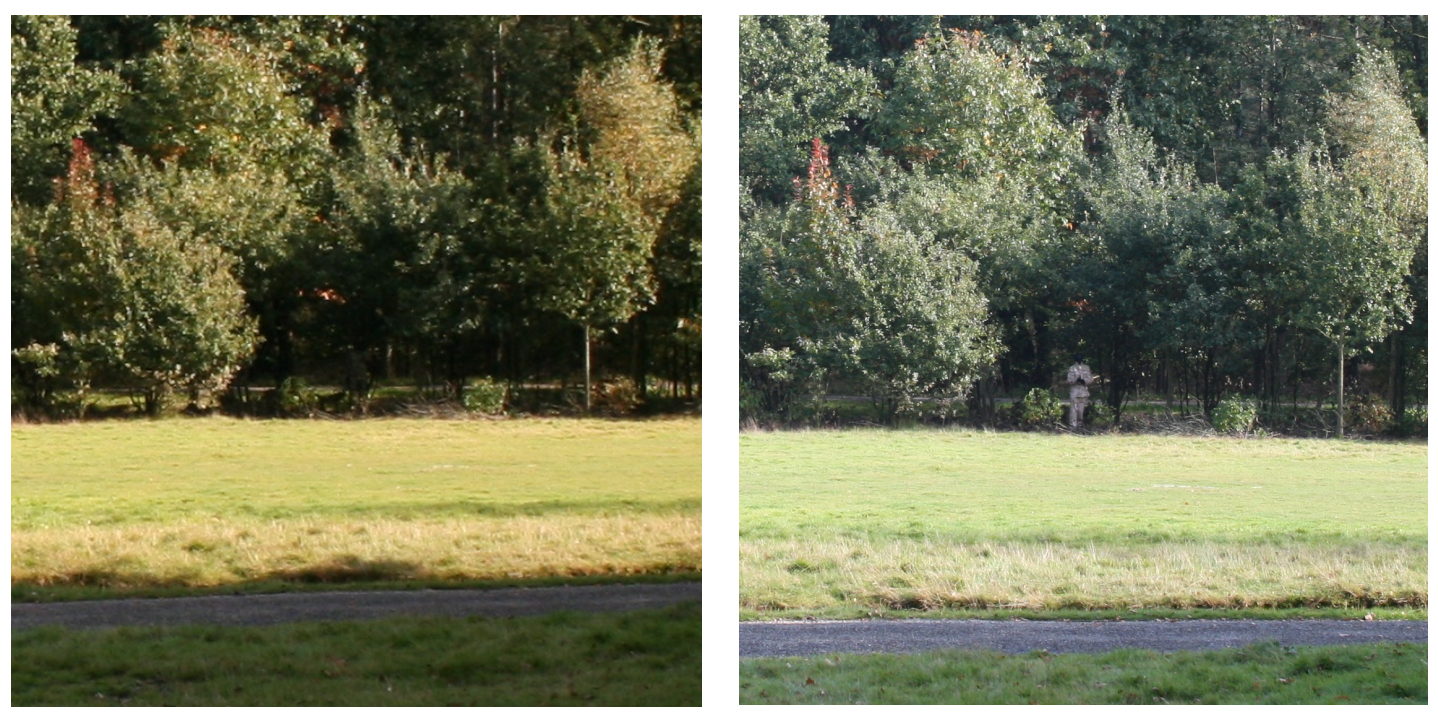

Figure 6. Target in woodland uniform (left) and kaki desert uniform (right).

The measurements (Figure 7) again reveal a large effect of motion, similar to what was reported in Experiment I. But, we also find clear effects of viewing distance and the type of camouflage. In static conditions, conspicuity for the desert uniform was a factor of 12.6 larger than for the woodland uniform. This factor was also high (1.7) for moving conditions. An inspection of the photos (Figure 6) suggests that the effect of uniform is governed by differences in luminance contrast. Indeed, the target luminance was 6 times higher for the desert uniform than for the woodland uniform (global contrast $\mathrm{C}=0.24$ and $\mathrm{C}=1.48$ for woodland and desert uniform, respectively). Obviously, the desert uniform has not been designed for use in woodland scenes. But these results do give quantitative insight into how ineffective the pattern of camouflage (colour and shape) can be if the mean luminance does not match the mean luminance of the background. 


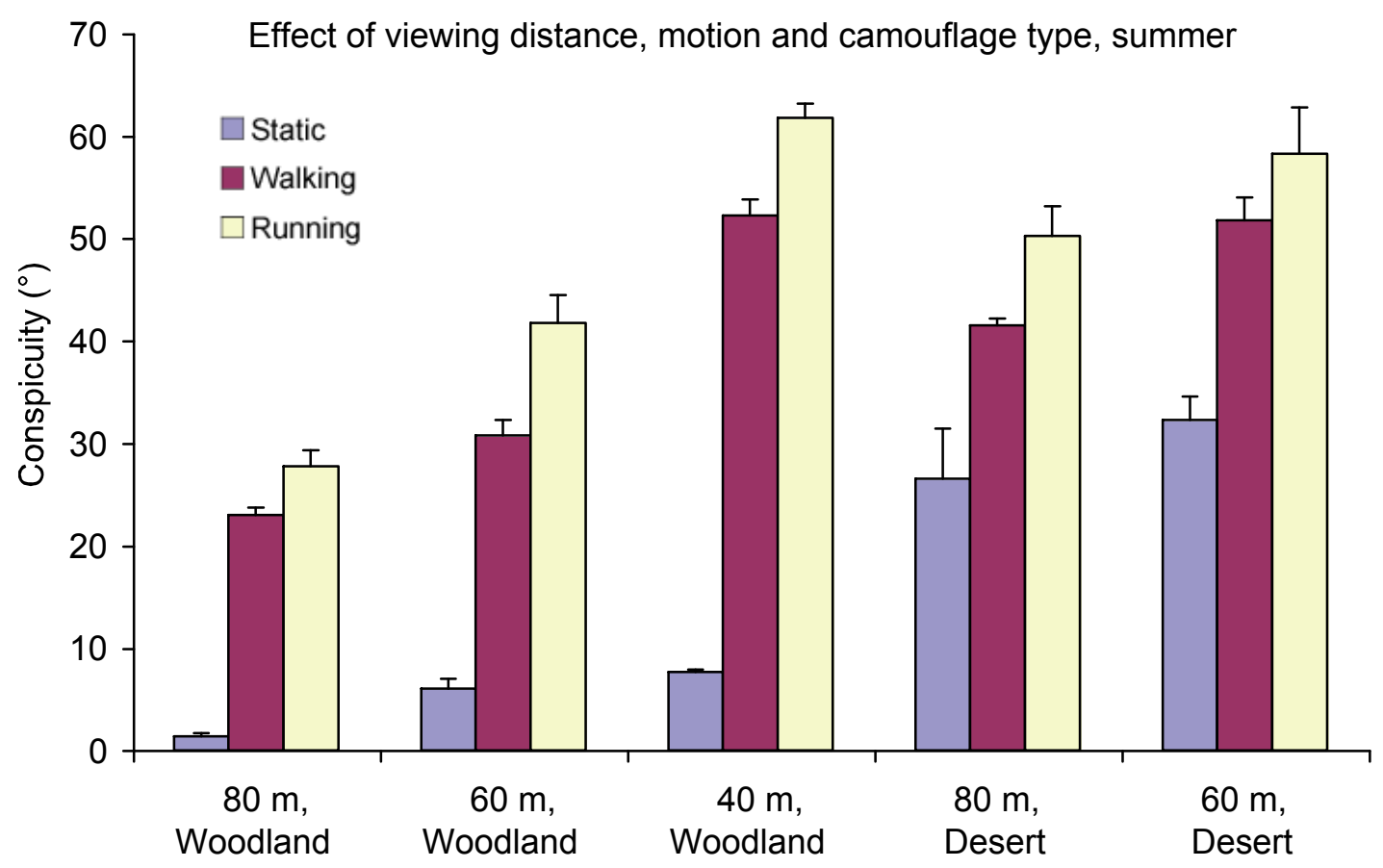

Figure 7. Effect of viewing distance, motion and camouflage type.

The data show only a small conspicuity difference between running and walking conditions. This observation is in line with literature that claims that conspicuity saturates at a retinal speed of about $0.8 \% \mathrm{~s}^{4}$. To check for such dependency on retinal speed, we replotted the data of Experiment II. Note, that although only three velocities were tested (0, 1.3 and 2.5 $\mathrm{m} / \mathrm{s}$ ), the variation in viewing distance created more than three retinal velocities.

The analysis of the effect of retinal target speed is facilitated by the fact that for conspicuity angles up to $40^{\circ}$ the absolute conspicuity is viewing-distance invariant $t^{2}$. Toet and Kooi defined absolute conspicuity as the spatial separation between final fixation and target, measured in the fronto-parallel plane through the target point. This could be approximated by Conspicuity $=\mathrm{d}^{*} \tan (\mathrm{a})$, where $\mathrm{d}$ is the target distance and a is the conspicuity angle. But for large conspicuity angles, this distance measure tends to increase asymptotically. A linear relation with conspicuity angle is assured by defining absolute conspicuity as the spatial separation measured in a plane through the target point, perpendicular to the direction bisecting target and fixation directions:

$$
\text { Consp }_{a b s}=2 * d * \sin (\alpha / 2)
$$

Figure 8 shows the speed-dependency of the absolute conspicuity for all data of Experiment II. The data nicely fall onto two curves: one for each type of camouflage pattern. The fact that points for different viewing distances fall onto one curve confirms the invariance with viewing distance for moving targets. 


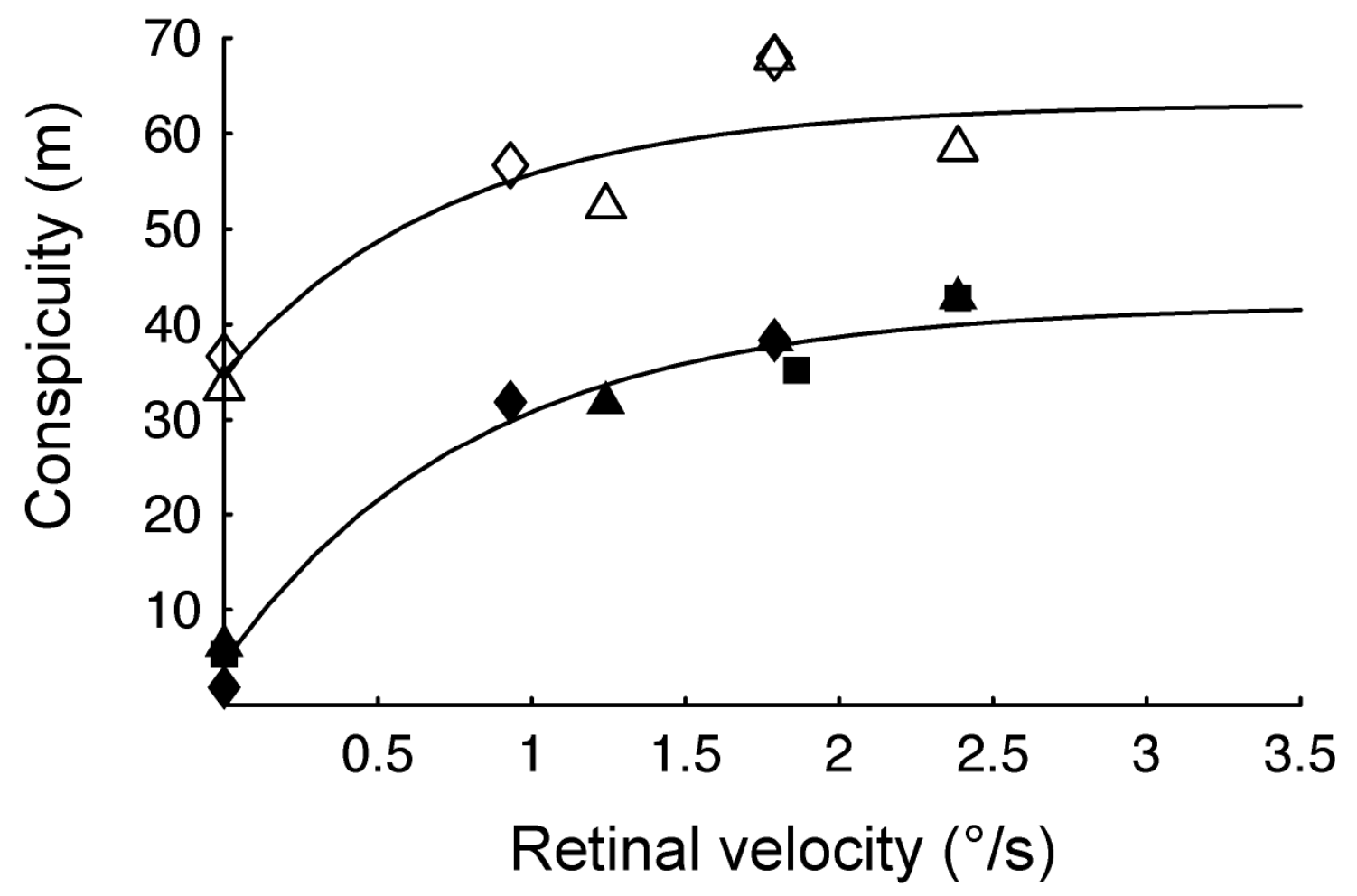

Figure 8. Effect of retinal target speed, camouflage type and viewing distance on absolute conspicuity according to Equation 3. Data for desert (top curve) and woodland (bottom curve) were fitted with logarithmic curves.

For woodland uniform, a three-parameter exponential fit reveals a function Consp[v] $=4.5+37.5^{*}(1-\operatorname{Exp}(-\mathrm{v} / 0.83)$ that starts deflecting at $0.83 \%$ s. For the kaki uniform the fitted curve was Consp[v] $=35.0+28.1 *(1-\operatorname{Exp}(-\mathrm{v} / 0.74)$, suggesting saturation starts at about $0.74 \%$ s. The conspicuity for moving soldiers thus clearly saturates as a function of retinal speed, in line with data by Mori et al. 1985 [9]. They found a sharp decrease in slope at $0.7 \%$, which has been proposed to reflect the existence of separate motion channels, one for low speeds and one for high speeds. The correspondence is surprising, because our trials were carried out in the field with natural scenes and complex biological motion instead of line translating artificial dot and line among other dots or lines. Also, the detection thresholds in our case were at much larger eccentricities (range between 20-60 $)$ than in Mori et al (range between 5 and $15^{\circ}$ ). Generally, receptive field size and contrast-sensitivity scale with retinal eccentricity, so differences in luminance contrast and size of the stimuli different.

To conclude, the data clearly show a large influence of luminance contrast on conspicuity and a large effect of retinal target speed. For modeling purposes it is safe to assume that the speed-dependency starts to saturate at a retinal target velocity of about $0.8^{\circ} / \mathrm{s}$. 


\section{EXPERIMENT III: EFFECT OF SEASON}

The measurements were repeated in winter, after the trees had lost their leaves. Note, location 4 was not measured. The results for summer and winter (Figure 9) show no effect of season, except at target position 1. At location 1 target conspicuity was clearly larger in winter, both in the static conditions and in the motion conditions. This increase may be a result of the absence of leaves in winter, so that the target and its immediate background were no longer in the shade.

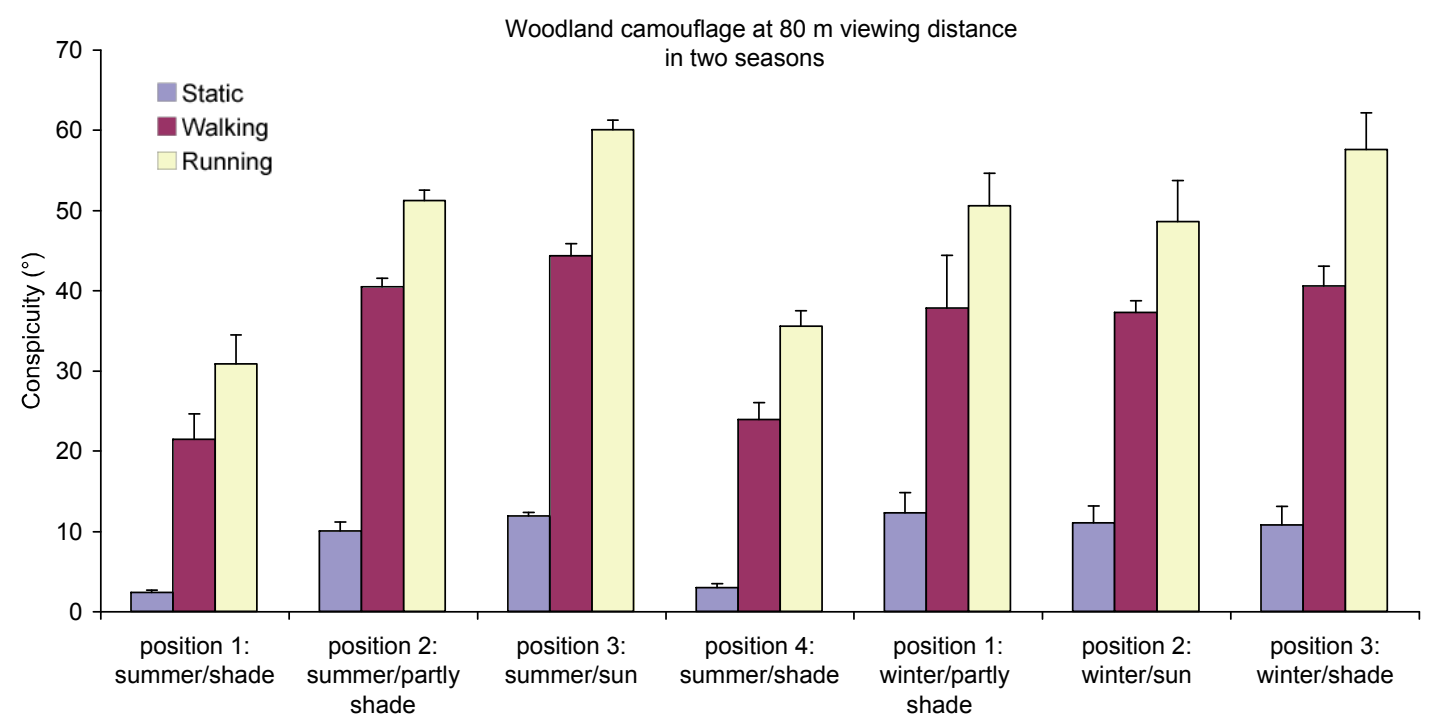

Figure 9. Conspicuity of a static or dynamic camouflaged soldier in winter as a function of position along the forest edge. Each point represents the average $( \pm 1$ S.E.) from two subjects and one measurement.

\section{EXPERIMENT IV: EFFECTS FOR THERMAL IMAGES}

The effect of motion was also measured from thermal images that had been captured during field trials. Data were captured at two locations; a deciduous forest at a viewing distance of $80 \mathrm{~m}$ and a pine tree forest at viewing distance of $230 \mathrm{~m}$ (see Figure 10). Also, the effect of season was tested and the difference between day and night, but only for static images (Figure 11).
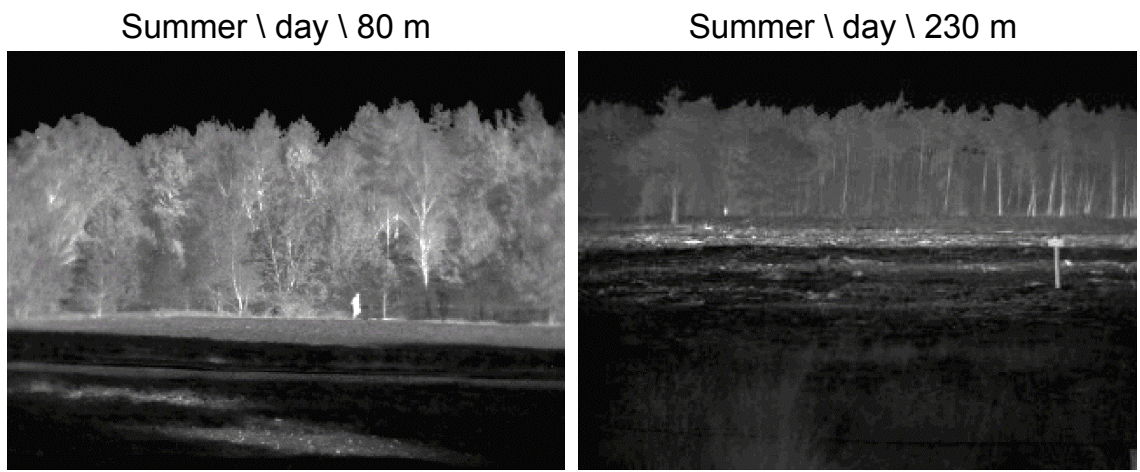

Figure 10. Example thermal images for $80 \mathrm{~m}$ (deciduous trees) and $230 \mathrm{~m}$ (pine trees) viewing distance. 

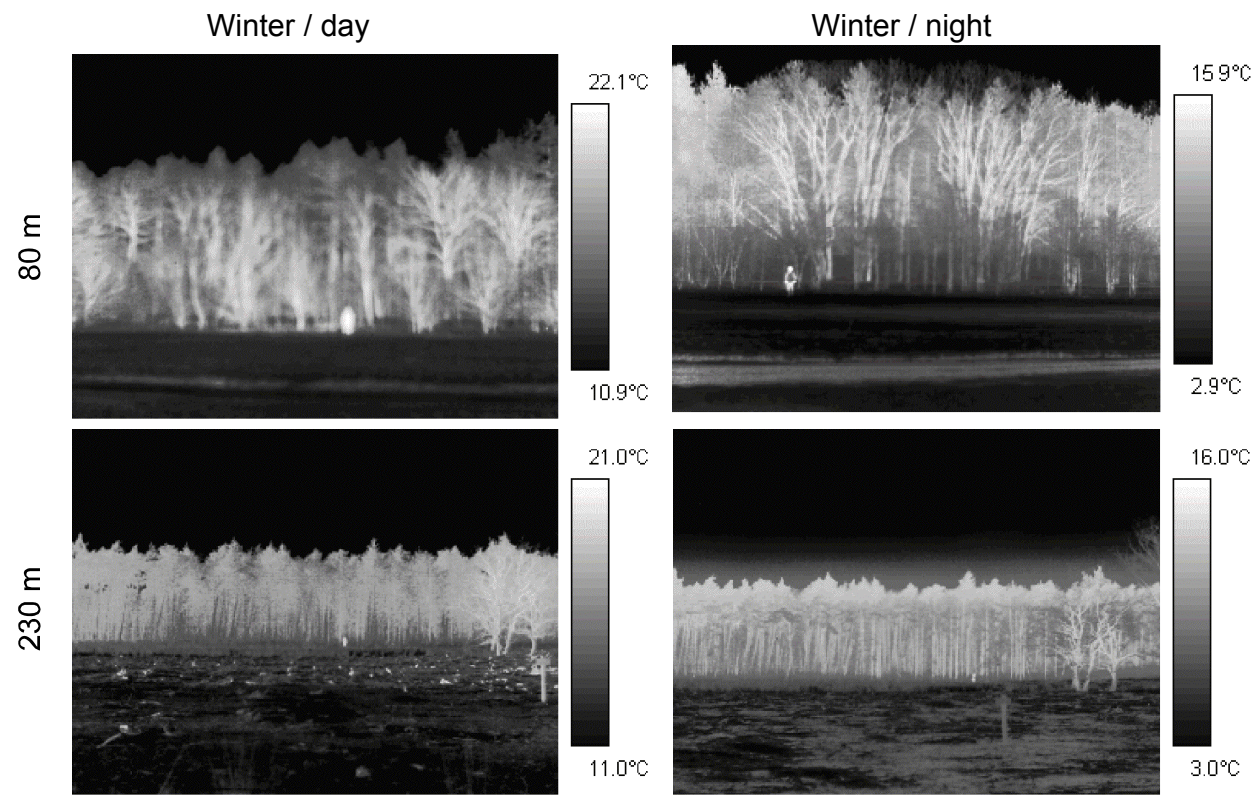

Figure 11. Example thermal images for viewing distance of $80 \mathrm{~m}$ (deciduous trees) and $230 \mathrm{~m}$ (pine trees) in winter during day and night. Note, the image at $80 \mathrm{~m}$ was slightly out of focus.

Figure 12 shows all data. Various interesting effects of motion, viewing distance and season can be observed. First of all, in early autumn, conspicuity was much lower for the $230-\mathrm{m}$ field than for the $80-\mathrm{m}$ field. An explanation for the reduced conspicuity is that the high contrast tree trunks of pine trees at $230 \mathrm{~m}$ look very similar to the target, thus creating much more clutter than the green of deciduous trees at $80 \mathrm{~m}$. Secondly, a clear effect of motion was found at both fields $(80$ and $230 \mathrm{~m}$, day, early autumn). Note, the effect of motion was much smaller at $230 \mathrm{~m}$, but this can be attributed to the three times smaller retinal target velocities.

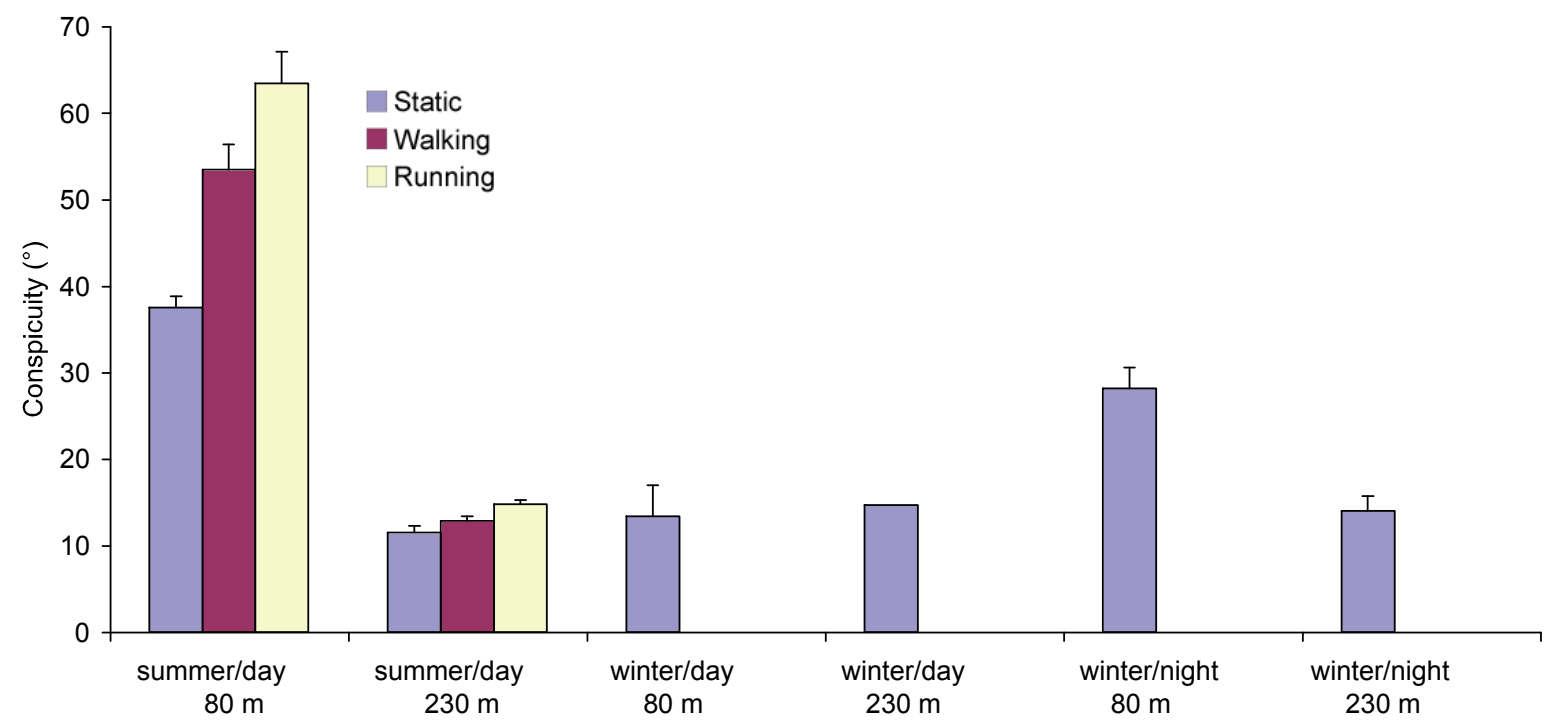

Figure 12. Effect of motion, season and time of day on the conspicuity from thermal images. 
Thirdly, a clear effect of season was found. For the $80 \mathrm{~m}$ scene (deciduous forest), the conspicuity was roughly three times lower in winter than in summer. The reason for the reduced conspicuity most likely is that tree trunks become visible in winter, thus adding clutter. This explanation is supported by the fact that the conspicuity for the coniferous trees, for which the tree trunks are visible all year, does not vary across season. Fourthly, the conspicuity for the deciduous forest edge $(80 \mathrm{~m})$ is increased during the night with relative to the day. The explanation here can be that the contrast was higher due to lower background temperature.

\section{CONCLUSIONS}

The results of the measurements of the thermal and visual conspicuity of moving camouflaged soldiers in the field lead to the following conclusions:

- Target motion significantly increases target conspicuity, independent of target contrast. Target conspicuity saturates as function of retinal target speed at about $0.8 \%$. The interaction with luminance contrast is highly non-linear.

- Effects of luminance contrast are limited and only evident for deciduous forest scenes, not for pine-tree scenes.

- The mean luminance of a camouflage pattern has a large effect on its conspicuity.

- Shading has a significant effect on conspicuity that can be captured by taking both local luminance contrast and global scene luminance into account.

- Seasonal influences on conspicuity can be large, mainly due to the increase in clutter in winter for deciduous type of forest.

- Variation in background temperature due to changes in season or time of day plays an important role in thermal target conspicuity. Not only can the thermal target conspicuity increase due to a lower background temperature, for instance during the night, but the target conspicuity can also decrease due to automatic scaling of the temperature range by the display software.

\section{REFERENCES}

1. AMSAA. IWARS Methodology Guide, July 2006, United States Army Materiel Systems Analysis Activity, Aberdeen Proving Ground, Maryland, USA, (2006).

2. Kooi, F.L. and Toet, A., Conspicuity: an efficient alternative for search time, In: A.G. Gale, I.D. Brown, C.M. Haslegrave \& S.P. Taylor (Ed.), Vision in Vehicles, pp. 451-462, Elsevier Science Ltd, Oxford, UK, 1999.

3. Lotens, W.A. A visual detection model for use in combat simulation, (Report TNO-DV 2009 A401), TNO Human Factors, Soesterberg, The Netherlands, (2009).

4. Mori, T., Visual conspicuity of a moving dot, horizontal line segment or vertical line segment, Vision Research, 25(8),pp. 1083-1088, 1985.

5. Toet, A. and Bijl, P., Visual conspicuity, In: R.G. Driggers (Ed.), Encyclopedia of optical engineering, pp. 29292935, Marcel Dekker Inc., New York, USA, 2003.

6. Toet, A., Kooi, F.L., Bijl, P. and Valeton, J.M., Visual conspicuity determines human target acquisition performance, Optical Engineering, 37(7) ,pp. 1969-1975, 1998.

7. Wertheim, A.H. A quantitative conspicuity index; theoretical foundation and experimental validation of a measurement procedure, (Report C-20), TNO Human Factors, Soesterberg, The Netherlands, (1989). 